\title{
Artemisia vulgaris efficacies against various stages of Aedes aegypti
}

\author{
Vika Ichsania Ninditya ${ }^{1}$, Endah Purwati ${ }^{1}$, Ajeng Tyas Utami ${ }^{1}$, Aprillyani Sofa Marwaningtyaz ${ }^{2}$, Nadia Khairunnisa Fairuz ${ }^{2}$ \\ Rini Widayanti ${ }^{1}$ and Penny Humaidah Hamid ${ }^{1}$ (D) \\ 1. Faculty of Veterinary Medicine, Universitas Gadjah Mada, Yogyakarta, Indonesia; 2. Study Program, Faculty of \\ Pharmacy, Universitas Gadjah Mada, Yogyakarta, Indonesia. \\ Corresponding author: Penny Humaidah Hamid, email: penny_hamid@ugm.ac.id \\ Co-authors: VIN: vika.ichsania.n@mail.ugm.ac.id, EP: endahp50@gmail.com, ATU: ajengtyasutami@gmail.com, \\ ASM: aprilly97@gmail.com, NKF: nadiacahya@gmail.com, RW: rini_widayanti@ugm.ac.id \\ Received: 18-02-2020, Accepted: 28-05-2020, Published online: 24-07-2020
}

\begin{abstract}
doi: www.doi.org/10.14202/vetworld.2020.1423-1429 How to cite this article: Ninditya VI, Purwati E, Utami AT, Marwaningtyaz AS, Fairuz NK, Widayanti R, Hamid PH (2020) Artemisia vulgaris efficacies against various stages of Aedes aegypti, Veterinary World, 13(7): 1423-1429.
\end{abstract}

\begin{abstract}
Background and Aim: Aedes aegypti is the vector of dengue fever, dengue hemorrhagic fever, chikungunya, and, most recently, Zika. Dengue fever is one of Indonesia's endemic diseases. The principal tool for preventing dengue is controlling Ae. aegypti by chemical insecticides since vaccine against dengue is still under research. However, Ae. aegypti developed resistance to various chemical insecticides worldwide. Therefore, research on alternate compounds as mosquito insecticides is urgently needed. This study demonstrated the efficacy of Artemisia vulgaris extract as larvicidal, ovicidal, adulticidal, repellency, and oviposition deterrent activity against Ae. aegypti.
\end{abstract}

Materials and Methods: A. vulgaris was obtained from Temanggung, Indonesia, while the eggs of Ae. aegypti were collected from Yogyakarta, Indonesia, and were hatched in Laboratory of Parasitology, Faculty of Veterinary Medicine, Universitas Gadjah Mada. Larvicidal activity was evaluated according to the WHO protocol; adulticidal activity was performed using the Centers for Disease Control protocol. Oviposition activity was evaluated using ovitraps added with A. vulgaris extract, complete protection time in the repellent assay was defined as the number of minutes elapsed between compound application and the landing of the first mosquito.

Results: A test of the larvicidal activity of $A$. vulgaris extract returned an $\mathrm{LC}_{50}$ of $65.8 \mathrm{ppm}\left(\mathrm{r}^{2}=0.9014\right)$ in $1 \mathrm{~h}$ and $18.6 \mathrm{ppm}$ $\left(\mathrm{r}^{2}=0.575\right)$ in $24 \mathrm{~h}$. A. vulgaris was effective as an adulticidal, demonstrating $\mathrm{LC}_{50}$ values of $11.35 \mathrm{mg}\left(\mathrm{r}^{2}=0.875\right)$ in $90 \mathrm{~min}$, $9.63 \mathrm{mg}\left(\mathrm{r}^{2}=0.924\right)$ in $105 \mathrm{~min}$, and $6.46 \mathrm{mg}\left(\mathrm{r}^{2}=0.925\right)$ in $120 \mathrm{~min}$. A. vulgaris at a concentration of $1000 \mathrm{ppm}$ was able to reach $96 \%$ of oviposition deterrent effect. The ovicidal assay, a concentration of $1000 \mathrm{ppm}$ resulted in $82.67 \%$ of eggs remaining unhatched. An extract concentration of $80 \mathrm{mg} / \mathrm{ml}$ achieved $63.3 \pm 3.5 \%$ biting repellency in adults.

Conclusion: This study gives a clear indication that $A$. vulgaris extract acts on Ae. aegypti at various developmental stages and is a potential alternative bioinsecticide for controlling this disease vector.

Keywords: Aedes aegypti, Artemisia vulgaris, bioinsecticide.

\section{Introduction}

Mosquito-borne diseases are endemic to more than 100 countries, resulting in the deaths of 2 million people every year and placing as many as 2100 million people around the world at risk [1]. More people in recorded history have died from diseases transmitted by mosquitoes than from fighting in all the wars combined [2]. Dengue fever is the most common mosquito-borne disease, affecting a wide spectrum of the global population [3]. It is common knowledge that mosquito-borne diseases are endemic to Indonesia, and the highest frequency of outbreaks occurring annually is those of dengue fever [4]. No specific treatment or vaccine for dengue has been found so far [5]. An extraordinary outbreak was reported to affect most

Copyright: Ninditya, et al. Open Access. This article is distributed under the terms of the Creative Commons Attribution 4.0 International License (http://creativecommons.org/licenses/ by/4.0/), which permits unrestricted use, distribution, and reproduction in any medium, provided you give appropriate credit to the original author(s) and the source, provide a link to the Creative Commons license, and indicate if changes were made. The Creative Commons Public Domain Dedication waiver (http:// creativecommons.org/publicdomain/zero/1.0/) applies to the data made available in this article, unless otherwise stated. of Indonesia, including 11 provinces, 12 districts, and three municipalities, with 8487 infection cases followed by 108 deaths in January 2016-February 2016. Patients aged 5-14 years were predominantly affected, comprising $43.44 \%$ of the total reported cases. The only available preventive measure against dengue virus transmission is the control of the disease vector [1]. The eradication of the disease vector is difficult in Indonesia, as in any other tropical country, because the climate supports the mosquito's life cycle. Moreover, global warming contributes significantly to the expanding mosquito population carrying dengue fever, yellow fever, malaria, and many other diseases that pose a risk to humans [6]. Vector control programs employing chemical and synthetic insecticides have long been utilized to prevent the transmission of mosquito-borne diseases. The use of chemical insecticides over a long period results in a multitude of problems, such as insecticide resistance, environmental pollution, and adverse impacts on humans and other organisms [7]. Botanical insecticides are considered to be environmentally-friendly and safe for other organisms [8]. The use of botanical remedies in control 
programs has been limited thus far; hence, no studies have shown vector resistance to botanical-based insecticides [9]. Plant extracts or phytochemicals are potential sources of commercial anti-mosquito bioactive compounds. Some phytochemical substances act as general toxicants against the adult and larval stages, while others act as repellents or attractants that interfere with the growth and development through the production of olfactory stimuli [1].

The genus Artemisia is one of the largest groups in the Asteraceae family, consisting of more than 800 species with a widespread global distribution [10]. Many of the identified Artemisia species grow in Asia, Europe, North and Central America, and Northern Africa [11]. Artemisia vulgaris is known locally as mugwort. Its essential oils are used as insecticidal, antimicrobial, and antiparasitic agents; fumigants; repellents of Musca domestica; hepatoprotectants; and analgesic agents [11]. Another species of Artemisia, Artemisia herba-alba was also reported to act as a vermifuge by reducing the egg and worm load of Heterakis gallinarum eggs in infected birds [12] and Haemonchus contortus [13]. The use of the herb A. absinthium, also known as wormwood, was also reported in ancient Egyptian times as being active against vermin, a common word for vector pests [14], and evidently exhibited strong larvicidal activities toward mosquitoes [15]. Artemisia is a very wellknown artemisinin compound that effectively reduces the malarial parasite burden. In addition, in the whole dried form, it acts synergistically to overcome malarial resistance to a single active compound $[11,16]$.

This study aimed to analyze the ovicidal, larvicidal, adulticidal, oviposition, and repellent activities of an A. vulgaris extract originating from Indonesia against Aedes aegypti mosquitoes.

\section{Materials and Methods}

\section{Ethical approval}

All of the experimental procedures reported herein were approved by the Ethics Committee for pre-clinical research of LPPT Universitas Gadjah Mada, Yogyakarta, under approval number 00076/04/ LPPT/VI/2017. Ethical clearance related to the human skin test (repellency assay) was issued by the committee of the Faculty of Medicine, Universitas Gadjah Mada, under approval number KE/FK/0622/EC/2017.

\section{Plant materials}

A. vulgaris was collected in March 2017 from Temanggung, Central Java Province, Indonesia, which is located at $7^{\circ} 19^{\prime} 30^{\prime \prime}$ latitude and $110^{\circ} 14^{\prime} 88^{\prime \prime}$ longitude. The identification of species was issued by the Department of Plant Systematic, Universitas Gadjah Mada, Yogyakarta, Indonesia. A total of $5 \mathrm{~kg} \mathrm{A.} \mathrm{vul-}$ garis were cleaned and dried using an oven at $55^{\circ} \mathrm{C}$ for 7 days. Dried leaves were ground into a powder in a grinding machine. Then, ethanol $95 \%$ was added to the powder for $A$. vulgaris extraction. The mixture was homogenized for $30 \mathrm{~min}$ and incubated for 1 day at room temperature. Complete removal of the filtrate was accomplished in a vacuum rotary evaporator. The extract was heated in a water bath at $70^{\circ} \mathrm{C}$. The final extract was obtained in extruded form and stored at $4^{\circ} \mathrm{C}$ until use in further experiments. One gram of the extract was dissolved in $100 \mathrm{ml}$ of ethanol to prepare a $1 \%$ stock solution $[17,18]$.

\section{Egg collection and mosquito rearing}

Eggs of Ae. aegypti were collected from several areas in Yogyakarta, Indonesia, using 200 ovitraps. The eggs were transferred to the Laboratory of Parasitology, Faculty of Veterinary Medicine, Universitas Gadjah Mada, Yogyakarta, for hatching. The eggs were placed in $20 \times 15 \times 5 \mathrm{~cm}$ plastic containers filled with $500 \mathrm{ml}$ tap water. Larvae were fed with chicken liver and maintained at $28^{\circ} \mathrm{C}$ and $70 \%-85 \%$ relative humidity, with a photoperiod of $12 \mathrm{~h}$ light and $12 \mathrm{~h}$ dark. The eggs hatched within $\pm 24 \mathrm{~h}$. The larvae developed into the third instar stage in $\sim 4$ days. Feeding was continued until the larvae transformed into pupae. Pupae were collected and transferred to glass beakers filled with $500 \mathrm{ml}$ of water [19].

\section{Larvicidal assay}

A larvicidal assay was performed using late third instar and early fourth instar larvae of Ae. aegypti. The larvicidal activity was evaluated according to the WHO protocol [20], as outlined below. Five larvae were transferred to a cup filled with $25 \mathrm{ml}$ of distilled water as a negative control; various concentrations of A. vulgaris extract $(1,5,10,50,100,500$, and 1000 ppm). Since temephos is known as common chemical larvicidal usually used [21], we used temephos as a positive control at concentrations similar to those of A. vulgaris extract. Three replicates were performed for each concentration, and larval mortalities were counted after $1 \mathrm{~h}$ and $24 \mathrm{~h}$ of exposure.

\section{Maintenance of adult mosquitoes}

On emergence from pupae, mosquitoes were transferred to $20 \times 20 \times 20 \mathrm{~cm}$ mosquito cages and fed with $10 \%$ sucrose solution until the time of testing [22].

\section{Centers for disease control (CDC) bottle bioassay}

The CDC bioassay was performed to determine the time required for the insecticide to penetrate a mosquito. The doses applied in this study were based on the CDC guidelines [23] as follows: $1.25 \mu \mathrm{g}, 2.5 \mu \mathrm{g}$, $5 \mu \mathrm{g}$, and $10 \mu \mathrm{g}$ for cypermethrin as positive controls; the ethanol bottle for the negative control; and A. vulgaris at concentrations of $10 \mu \mathrm{g}, 50 \mu \mathrm{g}, 100 \mu \mathrm{g}$, $500 \mu \mathrm{g}, 1000 \mu \mathrm{g}, 5000 \mu \mathrm{g}, 10,000 \mu \mathrm{g}, 50,000 \mu \mathrm{g}$, and $100,000 \mu \mathrm{g}$. Lower concentrations of A. vulgaris were not used. The CDC bottles were coated according to the CDC protocol [23]. The quantity of A. vulgaris extract was expressed as a mass because, following dilution in ethanol, the coated bottles were dried [23]. Between 10 and 20 unfed mosquitoes aged from 2 to 5 days were removed by aspiration and gently blown into the bottle. Susceptibility tests were performed 
according to the CDC protocol, in three replicates. Alive and dead mosquitoes were enumerated at the following intervals: $15,30,35,40,45,60,75,90,105$, and 120 min. "Dead" mosquitoes are mosquitoes that cannot stand and slide along the curvature of the bottle [23]. Total mortality in percent (Y-axis) versus time (X-axis) was then analyzed for all replicates [24].

\section{Oviposition}

Oviposition activity was evaluated using ovitraps filled with $100 \mathrm{ml}$ of tap water. Then, A. vulgaris extract was added to these ovitraps to obtain final concentrations of $100 \mathrm{ppm}, 500 \mathrm{ppm}$, and $1000 \mathrm{ppm}$. Ovitraps containing $1 \mathrm{ml}$ ethanol served as controls. Ovitraps filled with test and control solutions were placed in a mosquito cage containing 50 blood-fed females. Three replicates were performed for each concentration. Eggs were collected daily until no eggs were laid for at least $48 \mathrm{~h}$. The eggs were counted under a dissecting microscope [9]. Effective repellency (EF) was calculated using the following formula:

$$
\% \mathrm{ER}=\frac{N C-N T}{N C} \times 100 \%
$$

while the oviposition activity index (OAI) was calculated using the following formula:

$$
\mathrm{OAI}=\frac{N C-N T}{N C+N T}
$$

$\mathrm{NC}$ is the total number of eggs laid on the control paper. NT is the total number of eggs laid on the treatment paper [25]. Values of OAI +0.3 or above were considered to indicate an attractant and those -0.3 or below, a deterrent [26].

\section{Ovicidal assay}

One blood-fed female was transferred to a cup and allowed to lay eggs. For Ae. aegypti, the bottom of the cup was lined with filter paper on wet cotton (provided as an oviposition site). After 2 days, the eggs were collected and counted under a dissecting microscope. The filter papers yielded minimum 100 eggs per piece cut for further process. The eggs were submerged in three different concentrations of $A$. vulgaris extract: $100 \mathrm{ppm}, 500 \mathrm{ppm}$, and $1000 \mathrm{ppm}$. Ethanol served as a control. After $5 \mathrm{~h}$ of exposure, the eggs from each replicate were transferred to a different container filled with water for the hatching process. The hatched larvae were collected and counted daily until no larvae hatched for at least $48 \mathrm{~h}$. Hatched larvae were counted, and three replicates were performed for each concentration [9].

\section{Repellent assay}

One milliliter $(\mathrm{mg} / \mathrm{ml})$ of each test solution was smeared on the dorsal side of one hand (wrist to fingertips) of the subject. The concentration units of this part of the experiment were adjusted according to the WHOPES [27]. Thirty minutes after application, the hand was placed up to the wrist inside the repellent chamber through a hole for $3 \mathrm{~min}$ to allow the female mosquitoes to bite the subject. The tests were repeated at intervals of 30 or $60 \mathrm{~min}$. The landing of one mosquito during the 3-min test interval concluded the test for each repellent dose [28]. Complete protection time was defined as the number of minutes elapsed between compound application and the landing of the first mosquito. All experiments were performed in triplicate [5,27].

\section{Statistical analysis}

Data were analyzed with GraphPad software (GraphPad Inc., USA), including the determination of dose-response curves. The dose-response curve itself was defined by non-linear regression model of logarithmic dosage $(\mathrm{X})$ against responses $(\mathrm{Y})$. The lethal concentrations $50\left(\mathrm{LC}_{50}\right)$ and $\mathrm{LC}_{100}$, concentration, which causes the death of $50 \%$ and $100 \%$ of the tested mosquitoes, were drawn from the curve by GraphPad software.

\section{Results}

The larvicidal activity of $A$. vulgaris extract at different concentrations, i.e., 1, 5, 10, 50, 100, 500, and $1000 \mathrm{ppm}$, is presented in Figure-1. At a concentration of $1000 \mathrm{ppm}$, the application of the extract resulted in $100 \%$ larval mortality in the $1^{\text {st }} \mathrm{h}$ of observation. Total larval mortality was also achieved with the $10 \mathrm{ppm}$ concentration after $24 \mathrm{~h}$ of incubation. The $A$. vulgaris extract affected larval mortality in a concentration-dependent manner. Based on the mortality rate, the calculated $\mathrm{LC}_{50}$ values of $A$. vulgaris extract were $65.8 \mathrm{ppm}$ $\left(\mathrm{r}^{2}=0.9014\right)$ in $1 \mathrm{~h}$ and $18.6 \mathrm{ppm}\left(\mathrm{r}^{2}=0.575\right)$ in $24 \mathrm{~h}$. In addition, increasing the incubation period from 1 to $24 \mathrm{~h}$ significantly, by multiple t-tests, enhanced the extract's effect at $500 \mathrm{ppm}(\mathrm{p} \leq 0.0001), 100 \mathrm{ppm}$ $(\mathrm{p} \leq 0.0001), 50 \mathrm{ppm}(\mathrm{p} \leq 0.0001), 10 \mathrm{ppm}(\mathrm{p} \leq 0.0001)$, $5 \mathrm{ppm}(\mathrm{p} \leq 0.01)$, and $1 \mathrm{ppm}(\mathrm{p} \leq 0.1)$.

The activity of $A$. vulgaris against the adult stage of Ae. aegypti is presented in Figure-2a and b. The insecticidal effect of the extract against adult mosquitoes was also influenced by exposure time.

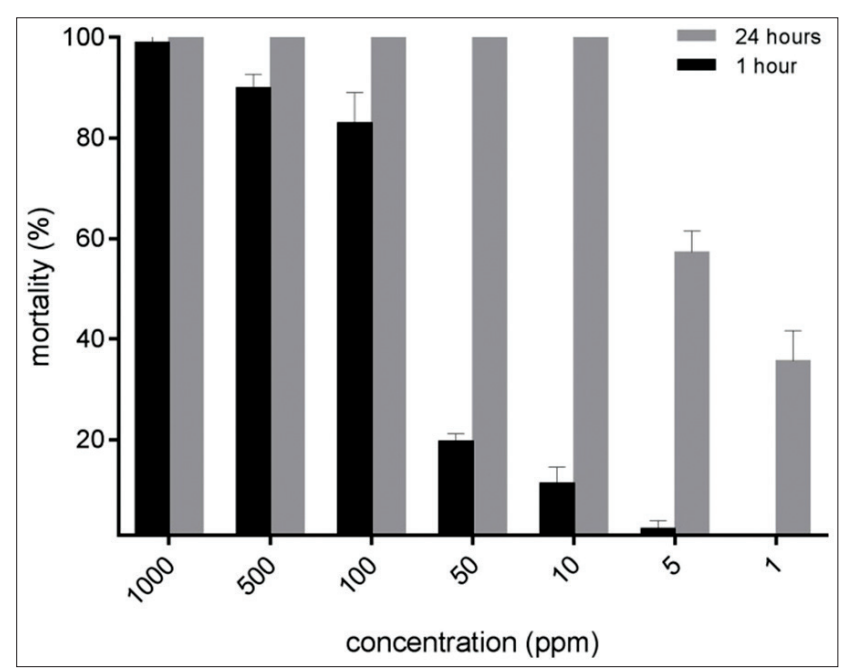

Figure-1: Larvicidal activity of Artemisia vulgaris against the tested Aedes aegypti. 


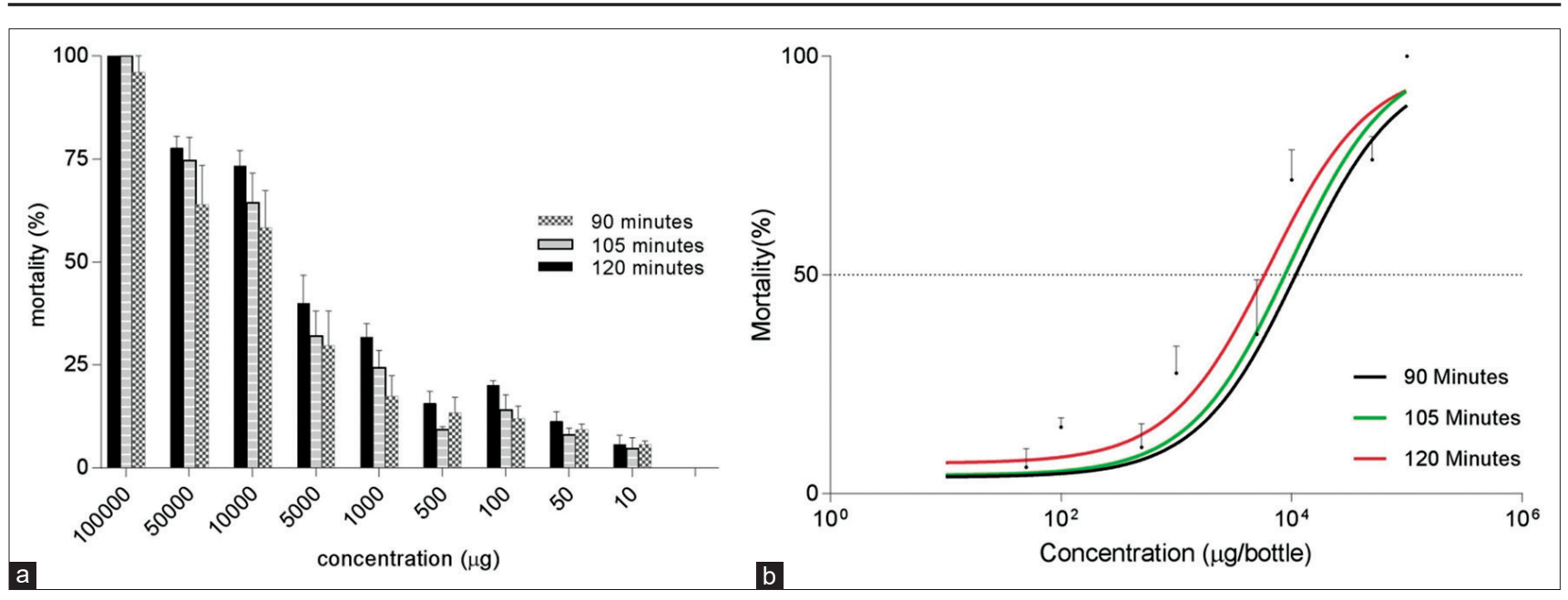

Figure-2: (a) Adulticidal activity of Artemisia vulgaris against the tested Aedes aegypti. (b) Dose-response analysis of the adulticidal effect of Artemisia vulgaris.

A dose-response curve (Figure-2b) showed that the $\mathrm{LC}_{50}$ values of $A$. vulgaris extract against adult $A e$. aegypti were $11.35 \mathrm{mg}\left(\mathrm{r}^{2}=0.875\right)$ in $90 \mathrm{~min}, 9.63 \mathrm{mg}$ $\left(\mathrm{r}^{2}=0.924\right)$ in $105 \mathrm{~min}$, and $6.46 \mathrm{mg}\left(\mathrm{r}^{2}=0.925\right)$ in $120 \mathrm{~min}$. However, no significant difference was found $(\mathrm{p} \leq 0.5)$ between the tested concentrations at any fixed exposure time $(90,105$, or $120 \mathrm{~min})$ in this experiment. No mortality was observed in the control group during the observation period.

The ovicidal assay demonstrated that $A$. vulgaris in the concentration of $1000 \mathrm{ppm}$ resulted in only $82.67 \%$ eggs unhatch (Figure-3). Ovicidal activity is $79.33 \%$ at a concentration of $750 \mathrm{ppm}$. In the concentration of $500 \mathrm{ppm}$, ovicidal activity is $44 \%$ (Table-1).

In this experiment, $A$. vulgaris showed a stronger repellent activity than the positive control during the observation period (Table-2). The tested concentrations were 20,40 , and $80 \mathrm{mg} / \mathrm{ml}$, which were lower than that of the positive control, i.e., a commercial cream containing N,N-Diethyl-meta-toluamide as $12 \%$.

\section{Discussion}

Insecticide resistance in Southeast Asia follows an increasing trend [29-35], mirroring the status of other types of resistance worldwide [36-41]. Resistance development is a serious problem since arthropod-borne diseases are largely controlled by insecticide-based vector action. To minimize the use of chemical compounds, natural herbs may serve as potential insecticides in the control of disease vectors, considering their abundance and safety. In this experiment, we evaluated $A$. vulgaris extract for its efficacy against the mosquito larval and adult stages, oviposition deterrent/attractant activities, ovicidal effect, and repellent activity. A. vulgaris showed prominent effects on Ae. aegypti stages imply its the potential use as non-chemical-based insecticide.

The larvicidal $\mathrm{LC}_{50}$ of $A$. vulgaris in this experiment was comparable to those reported by other studies conducted on the genus Artemisia. The $\mathrm{LC}_{50}$ of

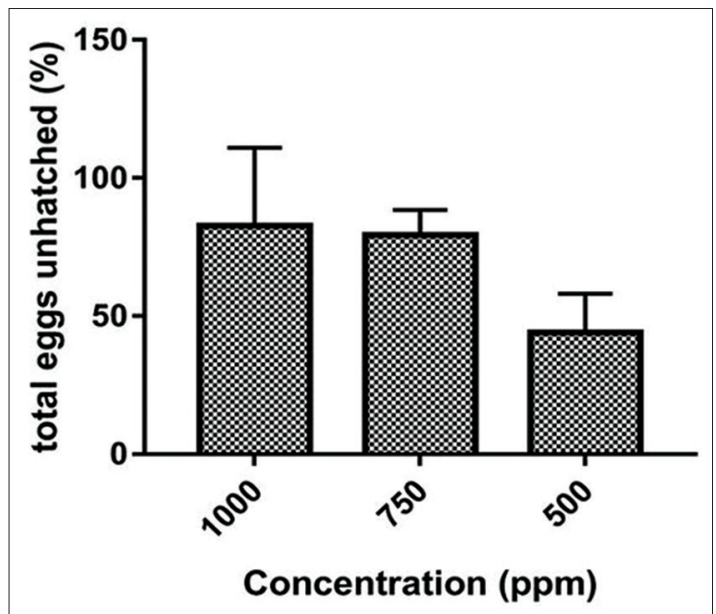

Figure-3: Ovicidal activity of Artemisia vulgaris to Aedes aegypti.

Table-1: Oviposition deterrent activity of Artemisia vulgaris.

\begin{tabular}{lcccc}
\hline $\begin{array}{l}\text { Concentration } \\
(\mathbf{p p m})\end{array}$ & \multicolumn{2}{c}{ Number of eggs } & ER (\%) & OAI \\
\cline { 2 - 4 } & Treated & Control & & \\
\hline 1000 & 168 & 3900 & 96 & -0.9174 \\
500 & 731 & 3970 & 82 & -0.689 \\
100 & 1197 & 4780 & 75 & -0.5995 \\
\hline
\end{tabular}

A. vulgaris against Ae. aegypti larvae was lower than those of $A$. nilagirica and $A$. annua in $24 \mathrm{~h}$ and $48 \mathrm{~h}$, respectively [9,19], benzene extract of Ervatamia coronaria and Caesalpinia pulcherrima [7], ethanolic extract of Tribulus terrestris [42], and nanoemulsion of Vitex negundo L essential oil [43]. The larvicidal $\mathrm{LC}_{50}$ of $A$. vulgaris extract against Ae. aegypti reported here is higher in $24 \mathrm{~h}$ exposure, i.e., $18.6 \mathrm{ppm}$ than that of $A$. vulgaris in essential oil form, $4.269 \mathrm{ppm}$ [44].

Insecticidal activity against adult $A e$. aegypti has also been reported in other species of the genus Artemisia, for example, A. nilagirica, which demonstrated an $\mathrm{LC}_{50} 242.52 \mathrm{ppm}$ [19]. A. vulgaris extract also showed deterrent, rather than attractant, activity 
Table-2: Repellent activity of Artemisia vulgaris extract.

\begin{tabular}{|c|c|c|c|c|c|c|}
\hline \multirow[t]{3}{*}{ Concentration } & \multicolumn{6}{|c|}{ Percent of repellency \pm SD } \\
\hline & \multicolumn{3}{|c|}{ Treated } & \multicolumn{3}{|c|}{ Positive control } \\
\hline & $30 \mathrm{~min}$ & $60 \mathrm{~min}$ & $90 \mathrm{~min}$ & $30 \mathrm{~min}$ & $60 \mathrm{~min}$ & $90 \mathrm{~min}$ \\
\hline $20 \mathrm{mg} / \mathrm{ml}$ & $58 \pm 6$ & $27 \pm 23.5$ & $1.7 \pm 2.9$ & $41.3 \pm 32.3$ & $46.7 \pm 30.5$ & $56.3 \pm 18.5$ \\
\hline $40 \mathrm{mg} / \mathrm{ml}$ & $65.3 \pm 13.3$ & $35 \pm 11.1$ & $21.3 \pm 27.1$ & $26.3 \pm 25.1$ & $49 \pm 17.0$ & $62.3 \pm 16.6$ \\
\hline $80 \mathrm{mg} / \mathrm{ml}$ & $63.3 \pm 3.5$ & $39.7 \pm 32.7$ & $26 \pm 23.9$ & $2.7 \pm 4.6$ & $10.3 \pm 17.9$ & $15.7 \pm 27.1$ \\
\hline
\end{tabular}

against $A$ e. aegypti oviposition at the three tested concentrations (Table-1). At a concentration of $1000 \mathrm{ppm}$, A. vulgaris inhibited oviposition by $96 \%$. The ovicidal assay demonstrated that $A$. vulgaris at a concentration of $1000 \mathrm{ppm}$ resulted in $82.67 \%$ of eggs left unhatched; at $750 \mathrm{ppm}$, this figure was $79.33 \%$ and at $500 \mathrm{ppm}, 44 \%$ (Figure-3). This result is similar to that reported for a $500 \mathrm{ppm}$ concentration of $A$. апnиa, which resulted in a hatching rate of $48.84 \%$ [9]. The deterrent effect of A. vulgaris at $500 \mathrm{ppm}$ was higher than that of Aegle marmelos $(71.79 \%)$ and Sphaeranthus amaranthoides (8.74\%), but lower than that of Limonia acidissima (100\%) in the ethanolic extract [25].

The repellent activity of the extract tended to decrease over a longer exposure period, in contrast to that of the positive control. Many bioactive compounds with repellent activity are highly volatile [45]; therefore, non-controlled release formulations confer a shorter period of protection. The formation of complexes with nanoparticles, such as silver, has been evidenced to increase efficiency and stability over time [46].

This experiment clearly demonstrated the adulticidal, larvicidal, ovicidal, and deterrent properties of A. vulgaris. The efficacy of potential insecticidal compounds in oviposition and ovicidal assays should also be considered to avoid the possibility of transovarial dengue virus transmission in the vector. Bioactive plant compounds in whole-extract form may act synergistically to produce higher effectiveness than individual compounds acting alone [47]. The extraction process is low-cost, simple, and rapid. It has the potential to be effective as an additional substance in a commercial formulation, since Ae. aegypti is reportedly resistant to pyrethroid-based insecticide, which is commonly used by the Indonesian people [28] The active components of $A$. vulgaris, i.e., camphor (26.99\%), $\alpha$-humulene $(0.72 \%), \quad \beta$-caryophyllene $(0.8 \%)$, and $\beta$-caryophyllene oxide $(15.87 \%)$, have demonstrated strong insecticidal activity [44]. In addition, the administration of a plant-based formulation is relatively risk-free. Moreover, A. vulgaris is consumed orally by local citizens as a traditional herbal for fever, headache, and stomachache. To the best of our knowledge, there has been no toxicity reported from citizens consuming A. vulgaris so far [48].

\section{Conclusion}

The development of resistance to chemical insecticides is growing rapidly worldwide. Natural herbs are considered as a promising new insecticide solution to control disease-carrying vectors. The effects of $A$. vulgaris in the stages of eggs and larvae can be developed further for bio-insecticides in water. The effectiveness of $A$ vulgaris in the adult stage can be developed into a spray-type insecticide. A. vulgaris also may be used as cream or lotion for skin repellent. Taken together, these results indicate that $A$. vulgaris can be applied to repel or inhibit Ae. aegypti in various stages of its lifecycle. In addition, there have been no reports so far on the toxicity of $A$. vulgaris to mammals. Further research is necessary to design a delivery method to enhance its efficacy and stability as a bioinsecticide.

\section{Authors' Contributions}

ASM and NKF performed an experiment on the extraction procedures. VIN, EP, and ATU tested to mosquitoes and repellency assay. PHH and VIN analyzed the data and involved in the project administration. PHH, RW, and VIN coordinated the work and wrote the manuscript. All authors read and approved the final version of the manuscript.

\section{Acknowledgments}

This study was partially funded by INSINAS grant no. 226/SP2H/LT/DRPM/III/2016 and Student Creativity Program by Ministry of Research, Technology, and Higher Education of the Republic of Indonesia.

\section{Competing Interests}

The authors declare that they have no competing interests.

\section{Publisher's Note}

Veterinary World remains neutral with regard to jurisdictional claims in published institutional affiliation.

\section{References}

1. Elumalai, D., Hemavathi, M., Hemalatha, P., Deepaa, C.V. and Kaleena, P.K. (2016) Larvicidal activity of catechin isolated from Leucas aspera against Aedes aegypti, Anopheles stephensi, and Culex quinquefasciatus (Diptera: Culicidae). Parasitol. Res., 115(3): 1203-1212.

2. Carde, R.T. and Resh, V.H. (2012) A Bird and Mosquito. In: A World of Insect. Harvard University Press, England. p174.

3. Wijayanti, S.P.M., Sunaryo, S., Suprihatin, S., McFarlane, M., Rainey, S.M., Dietrich, I., Schnettler, E., Biek, R. and Kohl, A. (2016) Dengue in Java, Indonesia: 
Relevance of Mosquito indices as risk predictors. PLOS Negl. Trop. Dis., 10(3): e0004500.

4. Karyanti, M.R. and Hadinegoro, S.R. (2009) Perubahan Epidemiologi Demam Berdarah Dengue Di Indonesia. Sari Pediatr, 10(6): 424-432.

5. Yimer, S. and Sahu, O. (2014) Anti-mosquito repellent from Artemisia annua. Int. J. Med. Clin. Sci., 1(1): 1-8.

6. Epstein, P.R. (2003) Climate change and human health risks and responses. Bull. World Health Organ., 83(5): 396-397.

7. Govindarajan, M., Mathivanan, T., Elumalai, K., Krishnappa, K. and Anandan, A. (2011) Mosquito larvicidal, ovicidal, and repellent properties of botanical extracts against Anopheles stephensi, Aedes aegypti, and Culex quinquefasciatus (Diptera: Culicidae). Parasitol. Res., 109(2): 353-367.

8. Jbilou, R., Amri, H., Bouayad, N., Ghailani, N., Ennabili, A. and Sayah, F. (2008) Insecticidal effects of extracts of seven plant species on larval development, alpha-amylase activity and offspring production of Tribolium castaneum (Herbst) (Insecta: Coleoptera: Tenebrionidae). Bioresour. Technol., 99(5): 959-964.

9. Cheah, S.X., Tay, J.W., Chan, L.K. and Jaal, Z. (2013) Larvicidal, oviposition, and ovicidal effects of Artemisia annua (Asterales: Asteraceae) against Aedes aegypti, Anopheles sinensis, and Culex quinquefasciatus (Diptera: Culicidae). Parasitol. Res., 112(9): 3275-3282.

10. Judžentienè, A. and Buzelyte, J. (2006) Chemical composition of essential oils of Artemisia vulgaris L. (mugwort) from North Lithuania. Chemija, 17(1): 12-15.

11. Abad, M.J., Bedoya, L.M., Apaza, L. and Bermejo, P. (2012) The Artemisia L. Genus: A review of bioactive essential oils. Molecules, 17(3): 2542-2566.

12. Seddiek, S.A.,Ali, M.M., Khater, H.F. andEl-Shorbagy, M.M. (2011) Anthelmintic activity of the white wormwood, Artemisia herba-alba against Heterakis gallinarum infecting Turkey poults. J. Med. Plants Res., 5(16): 3946-3957.

13. Varadyova, Z., Pisarcikova, J., Babjak, M., Hodges, A., Mravcakova, D., Kisidayova, S., Konigova, A., Vadlejch, J. and Varady, M. (2018) Ovicidal and larvicidal activity of extracts from medicinal-plants against Haemonchus contortus. Exp. Parasitol., 195: 71-77.

14. Khater, H. (2017) Introductory Chapter: Back to the Future Solutions for Parasitic Problems as Old as the Pyramids. IntechOpen, London.

15. Ali, S.I., Gopalakrishnan, B. and Venkatesalu, V. (2018) Chicory (Cichorium intybus) and wormwood (Artemisia absinthium) extracts exhibit strong larvicidal activity against mosquito vectors of malaria, dengue fever, and filariasis. Parasitol. Int., 67(6): 781-786.

16. Elfawal, M.A., Towler, M.J., Reich, N.G., Weathers, P.J. and Rich, S.M. (2015) Dried whole-plant Artemisia annua slows evolution of malaria drug resistance and overcomes resistance to artemisinin. Proc. Natl. Acad. Sci. U. S. A., 112(3): 821-826.

17. Perazzo, F.F., Lima, L.M., Maistro, E.L., Carvalho, J.E., Rehder, V.L.G. and Carvalho, J.C.T. (2008) Effect of Artemisia annua L. leaves essential oil and ethanol extract on behavioral assays. Rev. Bras. Farmacogn., 18(1): 686-689.

18. Azizi, K., Shahidi-Hakak, F., Asgari, Q., Hatam, G.R., Fakoorziba, M.R., Miri, R. and Moemenbellah-Fard, M.D. (2016) In vitro efficacy of ethanolic extract of Artemisia absinthium (Asteraceae) against Leishmania major L. using cell sensitivity and flow cytometry assays. J. Parasit. Dis., 40(3): 735-740.

19. Panneerselvam, C., Murugan, K., Kovendan, K. and Kumar, P.M. (2012) Mosquito larvicidal, pupicidal, adulticidal, and repellent activity of Artemisia nilagirica (Family: Compositae) against Anopheles stephensi and Aedes aegypti. Parasitol. Res., 111(6): 2241-2251.

20. World Health Organization. (2005) Guidelines for Laboratory and Field Testing of Mosquito Larvicides.
World Health Organization, Geneva.

21. Sarma, R., Adhikari, K., Mahanta, S. and Khanikor, B. (2019) Combinations of plant essential oil based terpene compounds as larvicidal and adulticidal agent against Aedes aegypti (Diptera: Culicidae). Sci. Rep., 9(1): 9471.

22. Kauffman, E., Payne, A., Franke, M.A., Schmid, M.A., Harris, E. and Kramer, L.D. (2017) Rearing of Culex spp. and Aedes spp. mosquitoes. Bio Protoc., 7(17): e2542.

23. Brogdon, W.G. and Chan, A. (2010) Guideline for Evaluating Insecticide Resistance in Vectors Using the CDC Bottle Bioassay. Centers for Disease Control and Prevention, Atlanta, USA.

24. Aïzoun., N., Aïkpon, R., Azondekon, R., Gnanguenon, V., Osse, R., Padonou, G.G. and Akogbéto, M. (2014) Centre for Di4sease Control and Prevention (CDC) bottle bioassay: A real complementary method to World Health Organization (WHO) susceptibility test for the determination of insecticide susceptibility in malaria vectors. J. Parasitol. Vector Biol., 6(3): 42-47.

25. Reegan, A.D., Gandhi, M.R., Paulraj, M.G. and Ignacimuthu, S. (2015) Ovicidal and oviposition deterrent activities of medicinal plant extracts against Aedes aegypti L. and Culex quinquefasciatus Say Mosquitoes (Diptera: Culicidae). Osong. Public Health Res. Perspect., 6(1): 64-69.

26. Elango, G., Bagavan, A., Kamaraj, C., Zahir, A.A. and Rahuman, A.A. (2009) Oviposition-deterrent, ovicidal, and repellent activities of indigenous plant extracts against Anopheles subpictus Grassi (Diptera: Culicidae). Parasitol. Res., 105(6): 1567-1576.

27. World Health Organization. (2009) Guidelines for Efficacy Testing of Mosquito Repellents for Human Skin. Control of Neglected Tropical Diseases (NTD), Who Pesticide Evaluation Scheme. World Health Organization, Geneva.

28. Msangi, S., Kweka, E. and Mahande, A. (2018) Repellent activity of TRIG (N-N diethyl benzamide) against man-biting mosquitoes. J. Trop. Med., 2018: Article ID 9037616.

29. Hamid, P.H., Prastowo, J., Ghiffari, A., Taubert, A. and Hermosilla, C. (2017) Aedes aegypti resistance development to commonly used insecticides in Jakarta, Indonesia. PLoS One, 12(12): e0189680.

30. Hamid, P.H., Prastowo, J., Widyasari, A., Taubert, A. and Hermosilla, C. (2017) Knockdown resistance $(k d r)$ of the voltage-gated sodium channel gene of Aedes aegypti population in Denpasar, Bali, Indonesia. Parasit. Vectors, 10(1): 283.

31. Wuliandari, J.R., Lee, S.F., White, V.L., Tantowijoyo, W., Hoffmann, A.A. and Endersby-Harshman, N.M. (2015) Association between three mutations, F1565C, V1023G and $\mathrm{S} 996 \mathrm{P}$, in the voltage-sensitive sodium channel gene and knockdown resistance in Aedes aegypti from Yogyakarta, Indonesia. Insects, 6(3): 658-685.

32. Ishak, I.H., Jaal, Z., Ranson, H. and Wondji, C.S. (2015) Contrasting patterns of insecticide resistance and knockdown resistance (kdr) in the dengue vectors Aedes aegypti and Aedes albopictus from Malaysia. Parasit. Vectors, 8: 181.

33. Yanola, J., Somboon, P., Walton, C., Nachaiwieng, W., Somwang, P. and Prapanthadara, L.A. (2011) Highthroughput assays for detection of the F1534C mutation in the voltage-gated sodium channel gene in permethrin-resistant Aedes aegypti and the distribution of this mutation throughout Thailand. Trop. Med. Int. Health, 16(4): 501-509.

34. Sayono, S., Hidayati, A.P., Fahri, S., Sumanto, D., Dharmana, E., Hadisaputro, S., Asih, P.B. and Syafruddin, D. (2016) Distribution of voltage-gated sodium channel (Nav) alleles among the Aedes aegypti populations in Central Java Province and its association with resistance to pyrethroid insecticides. PLoS One, 11(3): e0150577.

35. Hamid, P.H., Ninditya, V.I., Prastowo, J., Haryanto, A., Taubert, A. and Hermosilla, C. (2018) Current status of Aedes aegypti insecticide resistance development from Banjarmasin, Kalimantan, Indonesia. Biomed. Res. Int., 
2018: Article ID 1735358.

36. Alvarez, L.C., Ponce, G., Saavedra-Rodriguez, K., Lopez, B. and Flores, A.E. (2015) Frequency of V1016I and $\mathrm{F} 1534 \mathrm{C}$ mutations in the voltage-gated sodium channel gene in Aedes aegypti in Venezuela. Pest. Manag. Sci., 71(6): 863-869.

37. Linss, J.G., Brito, L.P., Garcia, G.A., Araki, A.S., Bruno, R.V., Lima, J.B., Valle, D. and Martins, A.J. (2014) Distribution and dissemination of the Val1016Ile and Phe1534Cys Kdr mutations in Aedes aegypti Brazilian natural populations. Parasit. Vectors, 7(15): 25.

38. McAllister, J.C., Godsey, M.S. and Scott, M.L. (2012) Pyrethroid resistance in Aedes aegypti and Aedes albopictus from Port-au-Prince, Haiti. J. Vector. Ecol., 37(2): 325-332.

39. Marcombe, S., Mathieu, R.B., Pocquet, N., Riaz, M.A., Poupardin, R., Selior, S., Darriet, F., Reynaud, S., Yebakima, A., Corbel, V., David, J.P. and Chandre, F. (2012) Insecticide resistance in the dengue vector Aedes aegypti from Martinique: Distribution, mechanisms and relations with environmental factors. PLoS One, 7(2): e30989.

40. Rodriguez, M.M., Hurtado, D., Severson, D.W. and Bisset, J.A. (2014) Inheritance of resistance to deltamethrin in Aedes aegypti (Diptera: Culicidae) from Cuba. J. Med. Entomol., 51(6): 1213-1219.

41. Li, C.X., Kaufman, P.E., Xue, R.D., Zhao, M.H., Wang, G., Yan, T., Guo, X.X., Zhang, Y.M., Dong, Y.D., Xing, D., Zhang, H.D. and Zhao, T.Y. (2015) Relationship between insecticide resistance and $k d r$ mutations in the dengue vector Aedes aegypti in Southern China. Parasit. Vectors, 8: 325.

42. El-Sheikh, T.M.Y., Al-Fifi, Z.I.A. and Alabboud, M.A. (2016) Larvicidal and repellent effect of some Tribulus terrestris L., (Zygophyllaceae) extracts against the dengue fever mosquito, Aedes aegypti (Diptera: Culicidae). J. Saudi Chem. Soc., 20(1): 13-19.

43. Balasubramani, S., Rajendhiran, T., Moola, A.K. and Diana, R.K.B. (2017) Development of nanoemulsion from Vitex negundo L. essential oil and their efficacy of antioxidant, antimicrobial and larvicidal activities (Aedes aegypti L.). Environ. Sci. Pollut. Res. Int., 24(17): 15125-15133.

44. Balasubramani, S., Sabapathi, G., Moola, A.K., Solomon, R.V., Venuvanalingam, P. and Diana, R.K.B. (2018) Evaluation of the leaf essential oil from Artemisia vulgaris and its larvicidal and repellent activity against dengue fever vector Aedes aegypti-an experimental and molecular docking investigation. ACS Omega, 3(11): 15657-15665.

45. Maia, M.F. and Moore, S.J. (2011) Plant-based insect repellents: A review of their efficacy, development and testing. Malar. J., 10(Suppl 1): S11.

46. Murugan, K., Priyanka, V., Dinesh, D., Madhiyazhagan, P., Panneerselvam, C., Subramaniam, J., Suresh, U., Chandramohan, B., Roni, M., Nicoletti, M., Alarfaj, A.A., Higuchi, A., Munusamy, M.A., Khater, H.F., Messing, R.H. and Benelli, G. (2015) Predation by Asian bullfrog tadpoles, Hoplobatrachus tigerinus, against the dengue vector, Aedes aegypti, in an aquatic environment treated with mosquitocidal nanoparticles. Parasitol. Res., 114(10): 3601-3610.

47. Gilbert, B. and Alves, L.F. (2003) Synergy in plant medicines. Curr. Med. Chem., 10(1): 13-20.

48. Nigam, M., Atanassova, M., Mishra, A.P., Pezzani, R., Devkota, H.P., Plygun, S., Salehi, B., Setzer, W.N. and Sharifi-Rad, J. (2019) Bioactive compounds and health benefits of Artemisia species. Nat. Prod. Commun., 14(7): 354. 